\title{
Correction: Characteristics associated with COVID-19 or other respiratory viruses' infections at a single-center emergency department
}

Donia Bouzid, Jimmy Mullaert, Quentin Le Hingrat, Odile Laurent, Xavier Duval, Xavier Lescure, Jean-François Timsit, Diane Descamps, Philippe Montravers, Christophe Choquet, Jean-Christophe Lucet, Enrique Casalino, Benoit Visseaux, ED influenza study group

In Table 2, the first column containing the variable names is missing. Please see the correct Table 2 here.

G openaccess

Citation: Bouzid D, Mullaert J, Le Hingrat Q, Laurent O, Duval X, Lescure X, et al. (2021)

Correction: Characteristics associated with COVID-

19 or other respiratory viruses' infections at a single-center emergency department. PLOS ONE 16(1): e0246458. https://doi.org/10.1371/journal. pone. 0246458

Published: January 27, 2021

Copyright: ๑ 2021 Bouzid et al. This is an open access article distributed under the terms of the Creative Commons Attribution License, which permits unrestricted use, distribution, and reproduction in any medium, provided the original author and source are credited. 
Table 2. Multivariate analysis for positive PCR for both periods (non-SARS-CoV-2 Respiratory Viruses (RV), and SARS-CoV-2) separately, and for SARS-CoV-2 vs RV in a modeled co-circulation period.

\begin{tabular}{|c|c|c|c|c|c|c|}
\hline & \multicolumn{2}{|c|}{$\begin{array}{c}\text { PCR }+ \\
\text { during RV period } \\
(\mathrm{N}=492)^{*}\end{array}$} & \multicolumn{2}{|c|}{$\begin{array}{c}\mathrm{PCR}+ \\
\text { during SARS-CoV-2 period } \\
(\mathrm{N}=582)^{*}\end{array}$} & \multicolumn{2}{|c|}{ 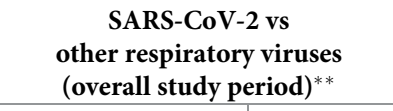 } \\
\hline & aOR (95\%CI) & $\mathbf{p}$ & aOR (95\%CI) & p & aOR $(95 \% \mathrm{CI})$ & p \\
\hline Age (per 10 years) & $0.89(0.80-1.00)$ & 0.041 & & & $0.80(0.72-0.89)$ & $<0.001$ \\
\hline Male gender & & & $2.23(1.53-3.25)$ & $<0.001$ & $1.64(1.10-2.44)$ & 0.015 \\
\hline Expectoration & $1.70(1.05-2.75)$ & 0.031 & & & $0.13(0.07-0.26)$ & $<0.001$ \\
\hline Fever & $1.60(1.08-2.38)$ & 0.02 & $3.33(2.25-4.97)$ & $<0.001$ & $3.27(2.17-4.94)$ & $<0.001$ \\
\hline Chills & & & $1.62(1.03-2.56)$ & 0.038 & & \\
\hline Myalgia & & & $1.72(1.10-2.70)$ & 0.017 & & \\
\hline Cough & $2.16(1.43-3.30)$ & $<0.001$ & & & & \\
\hline \multicolumn{7}{|l|}{ Diabetes } \\
\hline Chronic lung disease & & & $0.40(0.24-0.64)$ & $<0.001$ & $0.40(0.25-0.64)$ & $<0.001$ \\
\hline Respiratory rate $\left(\mathrm{min}^{-1}\right)$ & & & $1.06(1.02-1.09)$ & $<0.001$ & & \\
\hline Platelets (per 100G/L) & $0.69(0.54-0.85)$ & $<0.001$ & & & & \\
\hline Leucocytes (per G/L) & $0.97(0.93-1.01)$ & 0.11 & & & & \\
\hline
\end{tabular}

* Number of patients included in this analysis, excluding patients with missing values

** i.e. 40 and $45 \%$ for non-SARS-CoV-2 viruses and SARS-CoV-2, respectively

\section{Reference}

1. Bouzid D, Mullaert J, Le Hingrat Q, Laurent O, Duval X, Lescure X, et al. (2020) Characteristics associated with COVID-19 or other respiratory viruses' infections at a single-center emergency department. PLoS ONE 15(12): e0243261. https://doi.org/10.1371/journal.pone.0243261 PMID: 33270790 